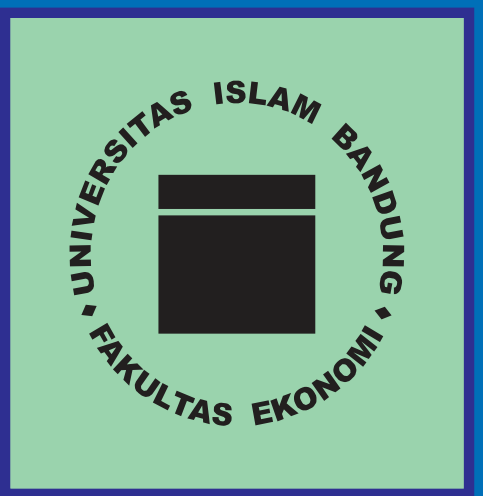

Vol.21 No.2

September 2020

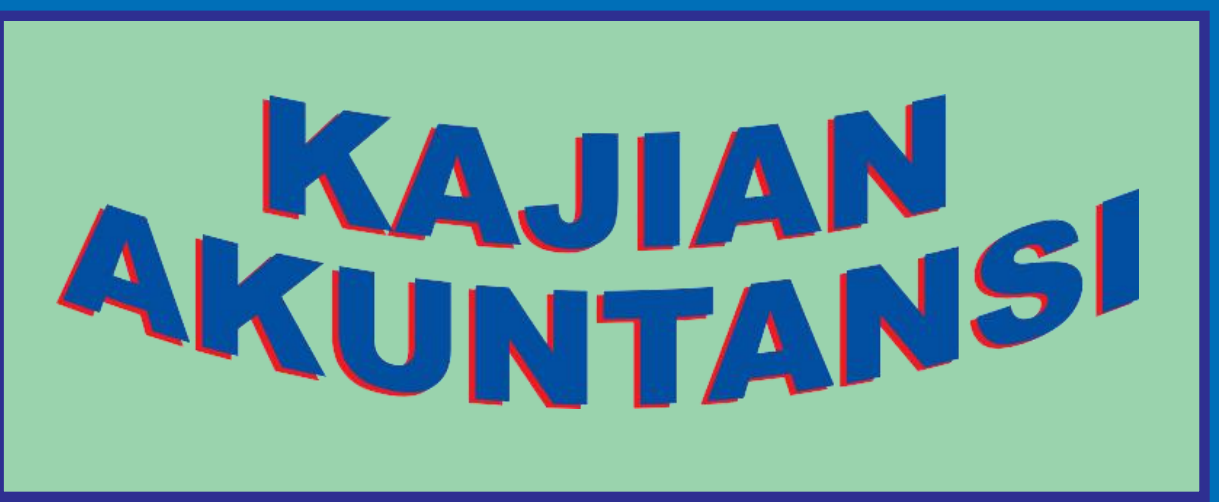

ISSN : 1693 - 0614 e-ISSN : 2581 - 074X
Deliana, Abdul Rahman

Ilham Hidayah Napitupulu, Anggiat Situngkir,

Chairunnisa Arfanni

Edi Sukarmanto, Magnaz Lestira Oktaroza, Karina Nur Astari

Eka Nurmala Sari, Muhyarsyah, Nunung Sri Wahyuni

Nurhayati, Muhammad Kevin Aprilio

Uli Wildan Nuryanto, Masyhudzulhak

Djamil MZ, Achmad Hidayat Sutawidjaya, Ahmad Badawi Saluy.

Riyang Mardini

Annisa Nadiyah

Rahmani

Diamonalisa Sofianty, Lena Herlina.
Efektivitas Audit Internal Pada Perguruan Tinggi Negeri Di Provinsi Sumatera Utara.

Pengaruh Transfer Pricing Dan Profitabilitas Terhadap Tax Avoidance.

Related Party Transaction Memperkuat Pengaruh Political Connection Terhadap Audit Delay?

Pengaruh Sistem Pengendalian Intern Pemerintah Dan Ketersediaan Anggaran Terhadap Efektivitas Penerapan Sistem Informasi Keuangan Daerah Pada Pemerintah Provinsi Dan Kabupaten/Kota Se-Sumatera Utara.

Pengaruh Rasio Solvabilitas Terhadap Kondisi Financial Distress

Implikasi Keunggulan Bersaing Terhadap Kinerja Organisasi Pada Sektor Industri Manufaktur Kimia di Provinsi Banten

Pengaruh Kinerja ICSR Terhadap Readability ICSR Menggunakan Gunning Fog Dan Flesch-Kincaid Indeks Dengan Size, Kinerja Keuangan, Leverage Dan Growth Sebagai Variabel Kontrol.

Dampak Covid-19 Terhadap Harga Saham Dan Kinerja Keuangan Perusahaan

Pengaruh Pengungkapan Corporate Social Responsibility Dan Mekanisme Good Corporate Governance Terhadap Tax Avoidance

Diterbitkan oleh :

ISSN

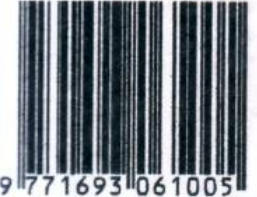

( P 2 U )

Pusat Penerbitan Universitas 


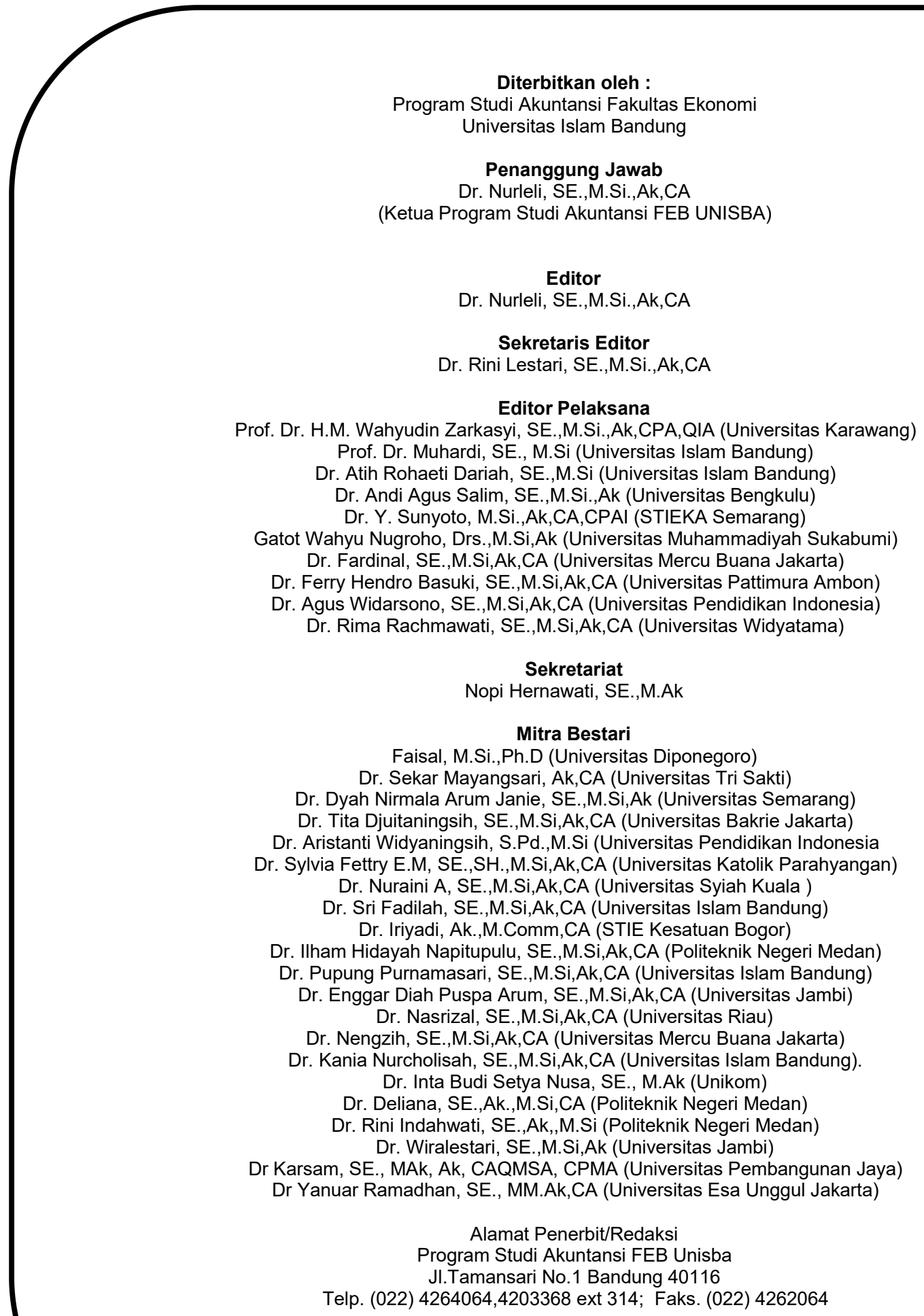

Terbit dua kali dalam setahun : Maret dan September Terbit pertama kali Maret 2003

Redaksi menerima naskah berupa artikel penelitian maupun artikel hasil pengkajian. Pendapat yang dimuat dalam jurnal ini sepenuhnya pendapat pribadi penulis ,

tidak mencerminkan pendapat redaksi,

dan telah disajikan menurut sistematika yang ditetapkan pada halaman akhir jurnal ini . 


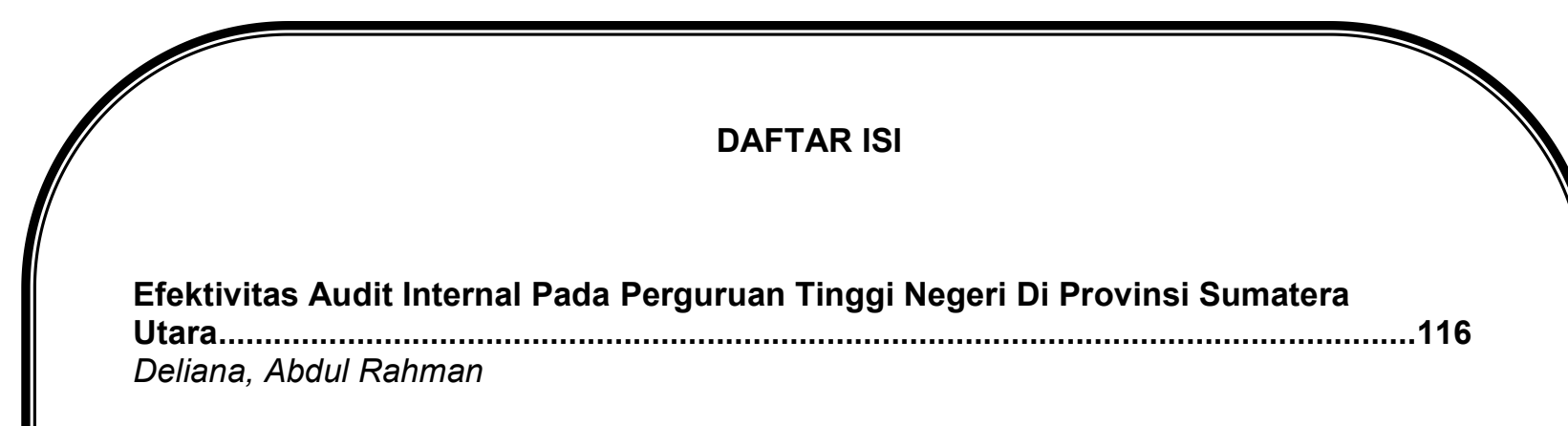

Pengaruh Transfer Pricing Dan Profitabilitas Terhadap Tax Avoidance .126

Ilham Hidayah Napitupulu, Anggiat Situngkir, Chairunnisa Arfanni

Related Party Transaction Memperkuat Pengaruh Political Connection

Terhadap Audit Delay?

Edi Sukarmanto, Magnaz Lestira Oktaroza, Karina Nur Astari

Pengaruh Sistem Pengendalian Intern Pemerintah Dan Ketersediaan Anggaran Terhadap Efektivitas Penerapan Sistem Informasi Keuangan Daerah Pada Pemerintah Provinsi Dan Kabupaten/Kota Se-Sumatera Utara.

Eka Nurmala Sari, Muhyarsyah, Nunung Sri Wahyuni

Pengaruh Rasio Solvabilitas Terhadap Kondisi Financial Distress Nurhayati, Muhammad Kevin Aprilio

Implikasi Keunggulan Bersaing Terhadap Kinerja Organisasi Pada Sektor Industri Manufaktur Kimia di Provinsi Banten.

Uli Wildan Nuryanto, Masyhudzulhak Djamil MZ, Achmad Hidayat Sutawidjaya,

Ahmad Badawi Saluy

Pengaruh Kinerja ICSR Terhadap Readability ICSR Menggunakan Gunning Fog Dan Flesch-Kincaid Indeks Dengan Size, Kinerja Keuangan, Leverage Dan Growth Sebagai Variabel Kontrol

Riyang Mardini

Dampak Covid-19 Terhadap Harga Saham Dan Kinerja Keuangan Perusahaan. Annisa Nadiyah Rahmani.

Pengaruh Pengungkapan Corporate Social Responsibility Dan Mekanisme Good Corporate Governance Terhadap Tax Avoidance.

Diamonalisa Sofianty, Lena Herlina I 


\title{
PENGARUH RASIO SOLVABILITAS TERHADAP KONDISI FINANCIAL DISTRESS
}

\author{
Nurhayati \\ Program Studi Akuntansi \\ Universitas Islam Bandung \\ nurhayatikanom485@gmail.com
}

\author{
Muhammad Kevin Aprilio \\ Program Studi Akuntansi \\ Universitas Islam Bandung \\ muhamadkevin1749@gmail.com
}

\begin{abstract}
This study aims to provide empirical evidence on the effect of solvency on financial distress in telecommunication companies listed on the IDX. Solvency ratio used a measuring instrument with the formula Debt Ratio. This study uses secondary data obtained from the website www.idx.co.id. The population used in this study were telecommunication sector companies listed on the Indonesia Stock Exchange for 3 years starting from 2015 to 2018. While the research sample was determined using the purposive sampling method, so that 14 sample companies were obtained. The method used in this research is descriptive descriptive method of quantitative approach. The method of analysis used in this research is linear regression analysis. The results of this study indicate that the solvency ratio has a significant effect on financial distress conditions. For future research, it is suggested to expand the sample of companies, replace the measurement variables, and replace or add independent variables.
\end{abstract}

Keywords: solvency ratio, financial distress.

\begin{abstract}
Abstrak
Penelitian ini ditujukan untuk memberikan hasil bukti empiris tentang pengaruh solvabilitas terhadap kondisi Financial Distress pada perusahaan sektor telekomunikasi yang terdaftar di BEI. Rasio Solvabilitas digunakan alat ukur dengan rumus Debt Ratio, Penelitian ini menggunakan data sekunder yang didapat dari website www.idx.co.id. Populasi yang digunakan dalam penelitian ini adalah perusahaan sektor telekomunikasi yang terdaftar di Bursa Efek Indonesia selama 3 tahun yang dimulai dari tahun 2015 sampai dengan 2018. Sedangkan sampel penelitian ditentukan dengan menggunakan metode purposivesampling, sehingga diperoleh 14 perusahaan sampel. Metode yang digunakan dalam penelitian ini metode deskrisi verifikatif pendekatan kuantitatif, MetodeAnalisis yang dipakai pada penelitian ini adalahan alisis regresi linier. Hasil penelitian ini menunjukan bahwa rasio solvabilitas memiliki pengaruh yang signifikanterhadap kondisi financial distress. Bagi penelitian berikutnya disarankan untuk memperluas sampel perusahaan, mengganti pengukuran variable, dan mengganti atau menambahkan variable independen.
\end{abstract}




\section{Kata Kunci : Rasio Solvabilitas, financial distress.}

\section{PENDAHULUAN}

BEI (Bursa Efek Indonesia) telah mencatatkan ada 600 perusahaan yang telah terdaftar di BEI. Dengan adanya BEI baik pemegang saham maupun masyarakat dapat memantau pergerakan dan kinerja keuangan perusahaan yang telah terdaftar di BEI. Salah satu manfaat perusahaan menjadi go-public adalah memperoleh sumber pendanaan baru. Perolehan dana dapat melalui penjualan kepada publik, mempermudah akses perbankan, dan mempermudah perusahaan agar dapatmemasuki pasar modal melalui sebuah penerbitan surtat utang baik dalam jangka waktu yang Panjang maupun pendek. Namun begitu perusahaan go-public selalu mendapatkan keuntungan. Sering kali keuntungan yang didapat oleh beberapa perusahaan tidak dapat memenuhi apa yang menjadi ekspektasi yang diharapkan oleh investor dan pemilik perusahaan. Jatuh bangun perusahaan memang suatu hal yang akan sering terjadi pada perusahaan. Tetapi jika perusahaan terus mengalami krisis kondisi keuangan, ini dapat menyebabkan investor untuk tidak akan menanamkan investasi kepada perusahaan, dan ini akan membuat perusahaan beradadalam keadaan financial distress.

Financial distress adalah keadaan dimana proses menurunnya posisi financial perusahaan yang dialami sebelum perusahaan bangkrut atau pun mengalami likuidasi (Platt dan Patt, 2002). Biasanya financial distress ini terjadi sebelum perusahaan dinyatakan mengalami kebangkrutan. Penyebab financial distress adalah karena perusahaan tidak mampu mengelola stabilitas kinerja keuangan perusahaan dimana perusahaan mengalami kegagalan dalam kegiatan yang dilakukan dan mengakibatkan pendapatan menurun. Hal ini memicu perusahaan mengalami kegiatan beberapa waktu tertentu.

Ditemukannya kesulitan kondisi pada operasi dan keuangan perusahaan menjadi subjek yang memiliki kerentanan terhadap analisis rasio keuangan (Altman, 2000). Ini menunju kan adanya hubungan yang erat antara rasio keuangan terhadap financial distress. Penggambaran rasio keuangan menunjukan keadaan perusahaan dengan laporan posisi keuangan dengan melakukan perbandingan yang setelahnya dihitung dan dibandingkan dengan rasio yang telah disepakati sesuai dengan standar. Dalam penelitian ini yang digunakan adalah rasio solvabilitas. 
Rasio solvabilitas merupakan suatu kemampuan entitas dalam melakukan pelunasan kewajiban lancar perusahaan dengan menggunakan harta lancernya (Tri wahyuningtias :2012). Ratio ini menyangkut kemampuan perusahaan untuk melakukan pembayaran hutangnya bila satu saat perusahaan mengalami kebangkrutan atau dibubarkan. Setiap penggunaan utang oleh perusahaan akan berpengaruh terhadap risiko dan pengembalian.

Permasalahan yang terjadi adalah perusahaan yang bergerak di bidang asuransi harus menjaga rasio solvabilitasnya diatas $120 \%$, dan pada 2017 Jiwasraya memiliki rasio solvabiliatsnya $123,6 \%$. Ini berarti perusahaan mampu menjaga rasio solvabilitasnya, yang sebelumnya sempat turun pada 2016 yaitu 200,15\%(CNBC).

\section{LANDASAN TEORI}

\subsection{Financial distres}

Financial distress adalah suatu tahap penurunan kondisi keuangan yang terjadi pada perusahaan sebelum terjadinya kebangkrutan ataulikuidasi" (Platt HD dan Platt MB 2002). Lalu Brahmana (2007) menyatakan bahwa "suatu perusahaan dikategorikan mengalami financial distress atau kesulitan keuangan apabila perusahaan tersebut menunjukkan angka negatif pada laba operasi, laba bersih dan nilai buku ekuitas serta perusahaan tersebut melakukan merger”. Menurut Fahmi (2011), Financial distress mempunyai 4 kategori yaitu kategori A (sangat tinggi), kategori B (tinggi), kategori C (sedang), dan kategori D (Rendah).

Salah satu cara untuk memprediksi financial distress hingga kebangkrutan pada perusahaan yaitu dengan menggunakan model Altman's Z-score Model Z-Score ini telah berkembang di berbagai negara. Ini merupakan suatu model yang multivariate dari financial distress yang sudah dilakukan pengembangan di berbagai negara. Altman $(1983,1984)$ telah melakukan sebuah percobaan untuk mensurvey model-model yang telah dilakukan pengembangan diberbagai negara yakni USA, German, Japan, Swissterzland, Irland, Australia, Brazil, France, Canda, United Kingdom, dan Netherland. Salah satu masalah yang dapat dibahas adalah apakah adanya keterkaitan rasio keuangan yang dapat digunakan dalam memprediksi kebangkrutan oleh semua negara, berikut ini adalah nilai Z-Score yang dikembangkan Altmans, yaitu:

$$
\mathrm{Zi}=(1,2 \mathrm{X} 1)+(1,4 \mathrm{X} 2)+(3,3 \mathrm{X} 3)+(0,6 \mathrm{X} 4)+(1,0 \times 5)
$$


Dimana :

\author{
X1 : (Aktiva Lancar-Utang Lancar)/Total Aset \\ X2 :Laba yang ditahan/Total Aset \\ $\mathrm{X} 3$ :Laba sebelum Bunga dan Pajak/TotalAset \\ X4 : Nilai Pasar Saham Biasa/Nilai buku total utang \\ X5 :Total dari Penjualan/TotalAset \\ Zi : Nilai Z-Score
}

Altman setidaknya memiliki 3 kategori yang dapat menjelaskan sebuah perusahaan itu mengalami kebangkrutan di masa mendatang, yaitu :

a. Apabila nilai $\mathrm{Z}$ lebih kecil daripada 1,81 ini bearti sedang mengalami distress, pada situasi ini, perusahaan mengalami finansial distress dan memiliki resiko yang tinggi sehingga dapat diperkirakan mengalami kebangkrutan

b. Apabila nilai 1,81 lebih kecil dibanding nilai $\mathrm{Z}$ sedangkan Nilai $\mathrm{Z}$ lebih kecil dibanding 2,99 $(1,81<\mathrm{Z}<2,99=$ Zone grey atau zona abu-abu), ini berarti perusahaan mengalami finansial distress keadaan sedang, di situasi ini perusahaan dapat ditangani sesuai penanganan yang diberikan oleh manajemen yang baik. Namun jika penanganan ini dirasa tidak tepat atau terlambat ini akan menjadikan perusahaan masuk ke resiko yang tinggi.

c. Apabila nilai $\mathrm{Z}$ diatas dari nilai 2,99 berarti perusahaan berada di area aman dari finansial distress, disituasi ini perusahaan sangat kecil untuk terjadinya kebangkrutan.

Berdasarkan Munawir (2007) analisis rasio merupakan sebuah analisis yang dimana menggambarkan antara hubungan antar jumlah melalui penggunaan alat analisis ratio agar dapat memberikan suatu gambaran baik buruknya keadaan suatu perusahaan. Sedangkan Etty dalam Orina (2013), mengungkapkan bahwa analisis ratio merupakan analisis yang digunakan untuk melakukan analisa antara hubungan data finansial dan agar dapat mengetahui hubungan antar pos baik didalam neraca ataupun laporan rugi laba yang dapat digunakan untuk mengetahui kondisi keuangan.

Adapun tujuan dari sebuah penerapan analisis rasio dalam laporan keuangan yaitu :

1. Rasio keuangan dapat membantu pihak manajer atau pimpinan dalam memahami informasi dari sebuah laporan keuangan. 
2. Membiasakan pimpinan dan manajer agar membuat keputusan untuk sebuah pencapaian dan prospek kedepanya.

Rasio solvabilitas adalah sebuah rasio yang digunakan untuk melakukan pengukuran terkait tingk aktiva yang harus dibiayai oleh utang (Kashmir, 2008:113). Definisi menurut Herispon rasio ini menyangkut jaminan, yang mengukur seberapa mampu perusahaan untuk membayar hutangnya apabila suatu saat perusahaan dibubarkan. Atau seberapa jauh perusahaan difinansir oleh pihak luar atau kreditur. Jumlah total hutang yang ada di tabel neraca akan memberikan hasil besarnya modal suatu pinjaman yang digunakan dalam sebuah operasional perusahaan. Jadi rasio solvabilitas atau leverage adalah sebuah rasio yang dapat dipakai atau dapat untuk mengukur apakah perusahaan mampu untuk membayar sisa hutangnya.

H1. Rasio Solavabilitas berpengaruh terhadap kondisi Financial Distress.

\section{METODE PENELITIAN}

\subsection{Metode penelitian}

Dalam penelitian ini penulis mengambil objek penelitian mengenai rasio solvabilitas dan kondisi financial distress. Adapun perusahaan yang dijadikan objek pada penelitian ini adalah perusahaan yang telah terdaftar di BEI (Bursa Efek Indonesia).

Dalam penelitian ini penulis menggunakan metode analisis deskriptif verifikatif dengan pendekatan kuantitatif.

\subsection{Operasionalisasi variabel}

Menurut Sekaran (2013:11) operasionalisasi variabel adalah definisi sebuah ide dalam istilah yang bisa diukur dengan mengurangi tingkat abstraknya, melalui penggambaran dimensi dan elemennya. Operasionalisasi variabel merupakan penjelasan dari masing-masing variabel yang digunakan dalam penelitian terdapat indikatorindikator yang membentuk variabel tersebut.

Tabel 1 berikut ini menggambarkan suatu ikhtisar mengenai variabel-variabel yang diukur dalam penelitian ini : 


\section{Tabel 1}

Operasionalisasi Variabel

\begin{tabular}{|c|c|c|c|c|}
\hline Variabel & Definisi Operasional & Dimensi & Indikaor & Skala \\
\hline $\begin{array}{l}\text { Rasio } \\
\text { Solvabilitas }\end{array}$ & $\begin{array}{l}\text { Rasio solvabilitas atau } \\
\text { rasio } \\
\text { merupakan rasio yang } \\
\text { digunakan rane } \\
\text { mengukur sejauh mana } \\
\text { aktiva perusahaan } \\
\text { dibiayai oleh utang }\end{array}$ & $\begin{array}{l}\text { Debt } \\
\text { Ratio }\end{array}$ & $\begin{array}{l}\text { 1. Total Liabilitas } \\
\text { 2. Total Aset }\end{array}$ & Rasio \\
\hline $\begin{array}{l}\text { Financial } \\
\text { Distress }\end{array}$ & $\begin{array}{l}\text { Financial distress adalah } \\
\text { tahap penurunan kondisi } \\
\text { keuangan yang terjadi } \\
\text { pada perusahaan } \\
\text { sebelum terjadinya } \\
\text { kebangkrutan } \\
\text { likuidasi }\end{array}$ & $\begin{array}{l}\text { Alltman } \\
\text { Z-Score }\end{array}$ & $\begin{array}{l}\text { Zi : Nilai Z Score } \\
\text { X1 : (Aktiva Lancar- } \\
\text { Utang lancar)/Total } \\
\text { Aset } \\
\text { X2 : Laba yang } \\
\text { ditahan/Total Aset } \\
\text { X3 : Laba sebelum } \\
\text { bunga dan pajak/Total } \\
\text { Aset } \\
\text { X4 : Nilai pasar } \\
\text { saham biasa/Nilai } \\
\text { buku total utang }\end{array}$ & Rasio \\
\hline
\end{tabular}

Sumber: Diolah

\subsection{Populasi dan Sampel}

Pada penelitian ini yang menjadi populasi adalah seluruh perusahaan telekomunikasi yang terdaftar di Bursa Efek Indonesia periode 2015-2018. Pada periode 2015-2018 ada 11 total perusahaan yang sesuai dengan kriteria. Pemilihan sampel dilakukan dengan menggunakan metode Purposive sampling dengan tujuan untuk mendapatkan sampel yang sesuai dengan kriteria yang ditentukan. Adapun kriterianya yakni :

1. Perusahaan yang terdaftar di BEI selama periode 2015-2018

2. Memiliki laporan tahunan dari 2015-2018

Dan berikut ini adalah daftar perusahaan yang dijadikan sampel dalam penelitian, disajikan dalam tabel berikut ini: 


\section{Tabel 2}

Pemilihan Sampel

\begin{tabular}{|c|c|l|}
\hline NO & $\begin{array}{c}\text { KODE } \\
\text { PERUSAHAAN }\end{array}$ & \multicolumn{1}{c|}{ NAMA PERUSAHAAN } \\
\hline 1 & TLKM & PT Telekomunikasi Indonesia (Persero) Tbk. \\
\hline 2 & BALI & PT Bali Towerindo Sentra Tbk. \\
\hline 3 & BTEL & Bakrie Telecom Tbk. \\
\hline 4 & EMTK & Elang Mahkota Teknologi Tbk. \\
\hline 5 & EXCL & XL Axiata Tbk \\
\hline 6 & FREN & Smartfren Telecom Tbk \\
\hline 7 & IBST & Inti Bangun Sejahtera Tbk \\
\hline 8 & ISAT & Indosat Tbk \\
\hline 9 & CENT & PT Centratama Telekomunikasi Indonesia Tbk \\
\hline 10 & SUPR & Solusi Tunas Pratama Tbk \\
\hline 11 & TBIG & PT Tower Bersama Infrastructure Tbk \\
\hline
\end{tabular}

Sumber : Bursa Efek Indonesia

\subsection{Rancangan Pengujian Hipotesis}

Alat uji statistik yang digunakan dalam pengujian hipotesis adalah uji asumsi klasik normalitas karena pengujian dengan Normal P-P Plot (Ghozali, 2009:174) untuk menguji pengaruh variable bebas terhadap varibel terikat. Persamaan regresi linier berganda sebagai berikut :

$$
\mathbf{Y}=\mathbf{a}+\mathbf{b X}+\mathbf{e}
$$

Keterangan :

$\mathrm{Y}=$ Variabel dependen (nilai yang diprediksikan)

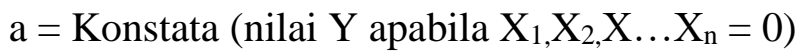

$\mathrm{b}=$ Koefisien regresi (nilai peningkatan ataupun penurunan)

$\mathrm{X}=$ Variabel independen

\subsection{Uji T}

Uji t bertujuan untuk mengetahui pengaruh antra variabel independen dengan variabel dependen secara parsial. Apabila sig t lebih besar dari 0,05 atau 5\% maka $\mathrm{H} 0$ diterima. Demikian pula sebaliknya jika sig t lebih kecil dari 0,05 atau 5\% maka H0 ditolak. Bila H0 ditolak ini berarti ada hubungan yang signifikan antara variabel independen terhadap variabel dependen (Ghozali, 2011:101). 


\section{HASIL DAN PEMBAHASAN}

\section{Uji Asumsi Klasik}

Hasil pembahasan meliputi uji asumsi klasik dan uji hipotesis. Uji asumsi klasik meliputi Uji Normalitas

Tabel 3

Uji Normalitas

\begin{tabular}{|ll|r|r|}
\hline & & \multicolumn{1}{|c|}{ Solvabilitas } & \multicolumn{1}{|c|}{ FD } \\
\hline $\mathrm{N}$ & & 44 & 44 \\
Normal Parameters ${ }^{\mathrm{a}, \mathrm{b}}$ & Mean & .635398 & 1.154916 \\
& Std. & .3889036 & .9261471 \\
& Deviation & & \\
Most Extreme Differences & Absolute & .181 & .165 \\
& Positive & .181 & .165 \\
& Negative & -.078 & -.112 \\
Kolmogorov-Smirnov Z & & 1.202 & 1.093 \\
Asymp. Sig. (2-tailed) & & .111 & .183 \\
\hline
\end{tabular}

Sumber : SPSS V17

Sesuai pada table diatas, terlihat bahwa hasil pengujian normalitas menggunakan one sample KS memiliki penyebaran normal dengan kata lain uji normalitas terpenuhi. Hal ini dilihat berdasarkan nilai sig yang diperoleh antar variable yaitu 0,111 dan 0,183. Dimana nilai ini lebih besar dibanding 0,05.

\section{Uji T}

\section{Tabel 4}

Uji T

\begin{tabular}{|c|c|c|c|c|c|c|c|}
\hline & \multicolumn{2}{|c|}{$\begin{array}{l}\text { Unstandardized } \\
\text { Coefficients }\end{array}$} & \multirow{2}{*}{$\begin{array}{c}\text { Standardized } \\
\text { Coefficients } \\
\text { Beta }\end{array}$} & \multirow[b]{2}{*}{$\mathrm{T}$} & \multirow[b]{2}{*}{ Sig. } & \multicolumn{2}{|c|}{ Collinearity Statistics } \\
\hline & B & Std. Error & & & & Tolerance & VIF \\
\hline $1 \quad$ (Constant) & .646 & .257 & & 2.514 & .016 & & \\
\hline Solvabilitas & .801 & .346 & .336 & 2.314 & .026 & 1.000 & 1.000 \\
\hline
\end{tabular}

Sumber : SPSS V17 
Berdasarkan tabel diatas, nilai t adalah 2.514 dan untuk nilai signifikansi uji adalah 0,026. Nilai signifikansi ini masih lebih kecil dibandingkan dengan nilai probabilitas 0,05. Berdasarkan hasil dapat diambil keputusan $\mathrm{H} 0$ ditolak dan $\mathrm{H} 1$ diterima. Ini berarti variable solvabilitas memiliki pengaruh yang signifikan terhadap kondisi finansial distress pada perusahaan sektor telekomunikasi yang terdaftar di BEI 20152018.

\section{KESIMPULAN DAN SARAN}

\subsection{Kesimpulan}

Berdasarkan hasil penelitian dari analisis data dan pembahasannya, maka penulis mengambil kesimpulan bahwa rasio solvabilitas berpengaruh signifikan terhadap kondisi financial distress pada perusahaan sektor telekomunikasi yang terdaftar di Bursa Efek Indonesia pada tahun 2015-2018.

\subsection{Saran}

Adapun saran penulis yang dapat diberikan dari hasil penelitian ini dalam aspek teoritis yaitu :

1. Untuk peneliti berikutnya sebaiknya dapat memperbanyak sampel yang diteliti sehingga dapat diperoleh hipotesis yang lebih akurat.

2. Peneliti berikutnya sebaiknya menambahkan atau menggantikan variable maupun indicator yang berbeda.

3. Peneliti berikutnya sebaiknya melakukan penelitian pada perusahaan lain dengan subsektor yang lebih banyak dari penelitian ini, dan juga serta periode penelitian yang lebih panjang dari penelitian ini.

\section{DAFTAR PUSTAKA}

Brahmana,Rayenda.K. 2007. .Identifying Financial Distress Conditionin Indonesia Manufacture Industry. Birmingham Business School, Uni versityBirmingham United Kingdom. 1-19.

Fahmi, Irham, 2011, Analisa Laporan Keuangan, Bandung: Alfabeta.

Kasmir, 2008, Analisa Laporan Keuangan, Yogyakarta: Liberty.

S. Munawir,2007,Analisis LaporanKeuangan,Yogyakarta: Liberty.

Fahmi, Irham. 2013. Analisis Laporan Keuangan.Bandung:Alfabeta. 
Harahap, Sofyan Syafri, 2013, Analisis Kritis Atas Laporan Keuangan ,Cetakan Kesebelas, Jakarta. Rajawali Pers.

Hanafi, Mamduh dan Halim, Abdul.2012. Analisis Laporan Keuangan. Edisi Ketiga. Cetakan Pertama. Yogyakarta.UPP Sekolah Tinggi Ilmu ManajemenYKPN.

Hanafi,Mamduhdan Abdul Halim.2003.Analisis Laporan Keuangan. Edisi Revisi. Yogyakarta: UPP AMP YKPN.

Rudianto. 2013.Akuntansi Manajemen Informasi untuk Pengambilan Keputusan Strategis. Jakarta: Erlangga

Subramanyam , John J. Wild.2012.Analisis Laporan Keuangan. Jakarta: SalembaEmpat.

Horne, James C. Van , Sinaga,Marianus,1994, Dasar-Dasar Manajemen Keuangan, Jilid Kedua, Edisi Keenam. Erlangga : Jakarta.

Agnes,Sawir.2008. Analisis Kinerja Keuangan dan Perencanaan Keuangan. Jakarta:PT Gramedia Pustaka Utama.

Hanafi, 2004. Manajemen Keuangan. Yogyakarta: BPFE UGM.

Sugiyono,2009, Metode Penelitian Kuantitatif, Kualitatif dan $R \& D$, Bandung:Alfabeta

Pyndyk, R. S. and D. L. Rubinfield. 1987. Econometric Models \& Economic Forecasts, 3rd ed. NY: McGraw-Hill Publishing, Inc. 